\title{
ANDROGINIA Y MATERNIDAD: UNA APROXIMACIÓN AL ENCUENTRO DE LO MASCULINO Y LO FEMENINO EN EL ARTE DEL SIGLO XX Y XXI
}

Androgyny and Motherhood: An Approach to the Encounter of the Masculine and the Feminine in the Art of the $20^{\text {th }}$ and $21^{\text {st }}$ Centuries

Belén León-Río ${ }^{1}$

Correo electrónico: belenleon@us.es

1. Profesora Titular de Universidad. Dpto. de Escultura e Historia de las Artes Plásticas. Facultad de Bellas Artes. Universidad de Sevilla. (Sevilla, España)

ORCID: http://orcid.org/0000-0001-8317-1005. ID SCOPUS: 57210125739. PUBLONS: https://publons.com/researcher/AAC-3634-2020/.

Recibido: 22/05/2020 Aceptado: 02/12/2020

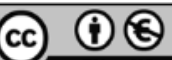

\footnotetext{
${ }^{1}$ Grupo de investigación «Técnicas del Bronce». Proyecto de Excelencia «Colada Automática de Procedimiento Eutéctico en la Fundición Artística» (P07-HUM-02497 - Investigador).
} 


\section{RESUMEN}

En nuestra sociedad, la diferencia entre hombres y mujeres se ha traducido ideológicamente en un lenguaje dual y contrapuesto en vez de buscar un término medio que una las oposiciones. El arte, sin embargo, ha encontrado dicho término medio a través de sus expresiones artísticas llenas de símbolos unitivos y totalizadores. Entre estos símbolos, destaca la androginia relacionada con el poder de lo femenino y el matriarcado, frente a un patriarcado trasnochado y enquistado en el pensamiento racional y lineal que tanto ha influido en nuestro modelo social. En este artículo, veremos cuáles son estos arquetipos, demostrando que habría una homogeneidad de la psique humana que produciría una abundante simbología relacionada con la maternidad y la bisexualidad, y que se produciría en distintos periodos de la historia como demuestran los temas míticos y legendarios, reflejándose en una heterogeneidad igualmente grande de la psique consciente de las mujeres artistas contemporáneas.

Palabras clave: maternidad; útero; andrógino; bisexualidad; arquetipo.

\section{ABSTRACT}

In our society, the difference between men and women has translated ideologically into a dual and opposed language instead of looking for a middle ground that unites oppositions. Art, however, has found this middle ground through its artistic expressions full of unifying and totalizing symbols. Among these symbols stands out the androgyny related to the power of the feminine and matriarchy, compared to an outdated patriarchy and entrenched in rational and linear thought that has influenced our social model so much. In this article we will see what these archetypes are, demonstrating how there would be a homogeneity of the human psyche that would produce an abundant symbology related to motherhood and bisexuality that would occur in different periods of history as demonstrated by mythical and legendary themes, reflecting in an equally large heterogeneity of the conscious psyche of contemporary female artists.

Keywords: Maternity; Uterus; Androgynous; Bisexuality; Archetype. 


\section{INTRODUCCIÓN}

C. G. Jung concibe las distintas épocas de la historia de la humanidad como el alma del ser humano que tendría una situación de consciencia especial y limitada y precisaría por ello de una compensación llevada a cabo por el inconsciente colectivo, de tal manera que el artista prestaría expresión a lo no manifestado de la situación temporal. El inconsciente penetraría en la consciencia cuando la persona se disuelve en la psique colectiva «una vez desmanteladas las barreras erigidas desde tiempo inmemorial, suele aflorar de manera espontánea, y hasta a veces se precipita en cierto modo inundando la consciencia» (1993: 197). Para este autor, el inconsciente colectivo debe entenderse como ese contenido del inconsciente que consistiría por una parte en las percepciones inconscientes de procesos reales externos y por otra en todas las reliquias de funciones de percepción y adaptación filogenéticas: «Una reconstrucción de la imagen inconsciente del mundo daría una imagen que mostraría cómo se veía la realidad externa desde tiempos inmemoriales. El inconsciente colectivo contiene o es un espejo que refleja el mundo. Constituye, en cierta medida, un mundo también, pero un mundo en imágenes» (213-214).

Entre estas imágenes. estaría el binomio anima-animus, que serían modelos universales de nuestra psique. C. G. Jung «empleó estos términos en relación con el latín animare, que significa vivificar», porque actuarían como «espíritus vivificadores» (Zweig, 2010: 251). Para C. G. Jung el ánima sería el arquetipo de la vida, ya que la vida llegaría al hombre a través del ánima, aunque crea que le llega por el entendimiento. De esta manera el hombre regiría la vida por el entendimiento, pero la vida viviría en él por el ánima. Mientras que, en la mujer, la vida le llegaría por la forma espiritual del ánimo a pesar de que crea que es el Eros el que le da la vida: «La mujer domina la vida, es decir vive habitualmente por el Eros, pero la verdadera vida, en la que ella es también víctima, le llega a la mujer por el entendimiento (mind) que en ella está corporizado por el Ánimo». (Jung, 1996: 410-411)

Los hombres, que generalmente se identifican con lo masculino, proyectarían su feminidad sobre las mujeres y, al contrario, las mujeres, «identificadas únicamente con lo femenino, proyectan su lado masculino e inconsciente sobre los hombres» (Zweig, 2010: 251). El anima-animus serían iguales y complementarios, constituyendo «un conjunto de naturaleza andrógina» (Walker, 2010: 81). En este sentido, Louise Bourgeois afirmaba: «Todos somos vulnerables de algún modo, todos somos masculinos y femeninos a la vez» 
(citado en Mayayo, 2002: 34). Esta integración de los contrarios tendría que ver según J. E. Cirlot con una «tensión energética espiritual determinante», nombrando a Blavatsky que decía como «todas las naciones consideraban a su primer dios como andrógino a causa de que la humanidad primitiva se sabía nacida de "lo mental” (Minerva surgiendo de la cabeza de Júpiter), como prueban los símbolos tradicionales» (Cirlot, 1969: 75).

\section{METODOLOGÍA}

El arte feminista de la actualidad estaría en gran medida conectado con el inconsciente, apareciendo una simbología relacionada con la gran diosa Madre y los mitologemas a ella asociados, como el cuerpo de la mujer, la maternidad, la sexualidad y la androginia. Analizando estas imágenes, pudimos comprobar como existían numerosos paralelismos entre las creaciones artísticas de las mujeres y los temas mitológicos estudiados por la escuela de psicología de C. G. Jung, que se había interesado en muchas ocasiones por el artista y sus obras donde este autor encontraba numerosos motivos que coincidirían con los arquetipos surgidos de los sueños y la imaginación activa de sus pacientes. Estas cuestiones nos llevaron a conjeturar que el arte, al igual que el rito y los mitos, nos ofrecería múltiples posibilidades de apertura de nuestra consciencia cuyos símbolos tenían la finalidad de transformación psicológica del individuo.

Este análisis nos mostró, además, como las mujeres artistas tendrían propensión, a través de sus acciones creativas, a manifestar un desarrollo psicológico, valiéndose de símbolos y arquetipos integradores de contenidos inconscientes que totalizarían al ser humano produciendo consecuencias muy importantes como la transformación de nuestra visión del mundo y de la sociedad, donde lo femenino estaría cobrando un renovado poder. Todo esto suscitó nuestro interés a investigar este tipo de manifestaciones plásticas donde las mujeres mediante la maternidad y la bisexualidad desafiarían nuestro modelo social fuertemente influenciado por el mundo de la razón y el patriarcado y donde intentarían transformar el modelo social, mostrando el poder de su lado masculino que nos vincularía con la diosa Madre. Este análisis lo hemos articulado en tres categorías que se exponen a continuación: 1 . El arte y el despertar de la diosa: sus símbolos unitivos de transformación; 2. Animus: el poder masculino en el arte de lo femenino; 3. El carácter bisexual del ser humano como meta unificadora. 


\section{EL ARTE Y EL DESPERTAR DE LA DIOSA: SUS SÍMBOLOS UNITIVOS DE TRANSFORMACIÓN}

M. L. von Franz llama la atención sobre el hecho de que en los últimos años los Estados están comenzando a preocuparse por el bienestar físico de la población, de manera que, por etapas, habría llegado «a ser cada vez más portador de la proyección de la madre, y menos de la imagen del padre. Lentamente y sin advertirlo, nos estamos deslizando hacia una situación matriarcal» (Franz, 1999: 315). También C. Zweig señala como se estaría produciendo un cambio en nuestra relación no solo con la materia y con la tierra sino también con nuestros cuerpos, donde lo femenino cambiaría el significado y la dirección de nuestra vida, iniciando «una nueva relación con el Yo. Con lo Otro y con lo Divino» (Zweig, 2010: 257), llamando la atención a como en la actualidad numerosas mujeres estarían redefiniendo su vida espiritual con el despertar de su parte femenina divina surgiendo así la Diosa, no solo en su concepción como figura única y transcendente sino también «como diosas plurales que representan las diversas energías de la vida. Ella nos trae una visión de la Mujer que viene de fuera de los muros del patriarcado. Afirma nuestros cuerpos, mentes, corazones, poderes y hermandad» (Zweig, 2010: 254).

En el arte también se estaría produciendo una elevación de la mujer, dándose ya pasos importantes en el porvenir de una nueva sociedad más subjetiva donde prime más lo femenino-maternal, habiendo un surgimiento y despertar de lo femenino divino mediante la representación de la Diosa que tendría que ver con la consciencia que mueve el universo y una vuelta a la Madre Tierra, como vemos en las experiencias de las mujeres artistas que se acercarían de manera inconsciente a sus propios arquetipos, como asevera Betsy Damon, que en 1977, tras realizar su performance titulada 7,000 Year-Old Woman, confesó sentirse como «una antigua diosa de la fertilidad» (citado en Reckitt y Phelan, 2005: 80).

C. G. Jung menciona como en épocas primitivas la materia se designaba como Gran Madre, habiendo perdido su significado emotivo, al igual que el espíritu que hoy en día se identifica con el intelecto y antes se identificaba con el Padre de Todo: «Ha degenerado en los limitados pensamientos del ego del hombre: la inmensa energía emotiva expresada en la imagen de "nuestro Padre” se disipa en la arena de un desierto intelectual» (1997: 92). Las grandes diosas madres habrían sido diosas de la fertilidad como «Gea, Rea, Hera, Deméter para los griegos, Isis entre los egipcios y en las religiones helenísticas, Ishtar 
entre los asiro-babilonios, Astarté para los fenicios [y los íberos], Kāli entre los hindúes» (Chevalier y Gheerbrant, 1999: 674). En todas las culturas aparecería el arquetipo de la Gran Madre constituyendo tanto a nivel religioso como psicológico el símbolo más universal. La madre divina en la teología hindú sería la fuerza vital universal, el principio espiritual que se expresaría con forma femenina:

La madre divina es como la serie continua que ata y sostiene el universo Prakriti y Māyā, unidad de todo lo que está manifestado, cualquiera que fuere su nivel de existencia, desde la simple apariencia hasta la pura ilusión. Es la conciencia de la manifestación, del yo de Shiva manifestado en la indefinitud de las apariencias, de esas olas de potencia energética que son los seres, de la materia precipitada y de fugitivas centellas. Es la conciencia de la totalidad manifestada. (Chevalier y Gheerbrant, 1999: 675)

N. Sorrosal señala como el patriarcado, en relación con la maternidad, «no quiere que resucitemos a la Madre» (Sorrosal, 2019: 39), afirmando como las mujeres estarían llevando a cabo «una revolución silenciosa, amorosa y pacífica. Es una revolución doméstica, en el sentido más sublime del término» (Sorrosal, 2019: 38). Para L. Irigaray el movimiento ligado a la vida, el devenir, existe cuando gobierna la diosa, la musa, en cambio el hombre se entrega «a la construcción de un mundo de artificios, a la elaboración de un cosmos de palabras en el que va a extraviarse, engañado por su propia palabra» (2016: 40). La diosa, la naturaleza, sería la que nos inspira, pero el hombre occidental no es capaz de reconocerlo, se ha ido alejando paulatinamente de su alrededor sin encontrar acertadamente su verdadera expresión: «Replegado sobre sí mismo, ha ido sustituyendo la percepción del mundo exterior por un universo de representaciones, progresivamente desvinculado de lo real». (42)

En la actualidad, existiría una sobrevaloración de lo racional, lo competitivo y lo lineal. Sin embargo, las mujeres a través de sus creaciones comienzan a manifestar sus emociones e intuición, impregnando a la sociedad en este sentido. La obra artística de Miriam Schapiro sería un claro exponente, en tanto que la creadora expresa su sensibilidad femenina mediante un estilo propio de collages a los que denomina femmages, empleando materiales y técnicas artesanales propias de la mujer como el ensamble con telas. Asimismo, también fue una de las primeras artistas que aplicaría en 1967 el software informático en su obra titulada $O X$, en la que representa los órganos genitales femeninos mediante una composición geométrica en forma de X. Esta imagen 
simbólica tan peculiar en el arte barroco se relacionaría con el Yoni, el vaso sagrado, el grial, la copa o el cáliz, símbolos «de la madre primordial, nutricia y protectora» (Durand, 1981: 243). La copa sería el seno materno y el útero, sede de las transformaciones. En la filosofía hermética de la alquimia el principio femenino tendría una gran importancia siendo el vaso en el que debían cumplirse las transformaciones de la materia, correspondiéndose con el Ântrôpos, y el universo material como microcosmos: «El vaso hermético redondo, en que se cumple la misteriosa transformación, significa la Divinidad, el Alma (platónica) del mundo y la Totalidad del ser humano». (Jung, 1995: 253)

Para C. G. Jung la supervivencia o la resurrección inconsciente del simbolismo del vaso sería una prueba de un reforzamiento del principio femenino en la psicología masculina del pasado. El anima producida por la psique humana simbolizaría el eterno femenino siendo una imagen numinosa que las mujeres artistas representan en muchas ocasiones como madre. El anima tendría un poder numinoso sobre hombres y mujeres porque ambos «han crecido en el vientre de una mujer y, excepto en casos de severa privación, han sido nutridos, cuidados y alimentados principalmente por mujeres en sus primeros años de vida» (Wehr. 2010: 69). Todo esto explicaría «el énfasis de la literatura en imágenes del ánima, en contraste con las imágenes del animus. La experiencia de la madre es básicamente primaria y numinosa debido a su naturaleza esencial, sea cual sea nuestro sexo» (Wehr. 2010: 69). Según C. G. Jung el símbolo de la madre como anima tendría que ver con el inconsciente, de manera que el anima puede representar a la madre mediante dos aspectos encontrados de totalidad, uno constructivo y otro destructivo: la madre es, por un lado, la seguridad, el alimento, el amor, el cobijo, el abrigo, el calor y la ternura frente a una madre devoradora y castradora. Esta ambivalencia se correspondería con el mar y la tierra, en el sentido de que una y otra son receptáculos y matrices de la vida, como vemos en el fotomontaje de Mary Beth Edelson realizado en 1975 Goddess Head, donde se representa a ella misma desnuda y con una cabeza en forma de caracola fosilizada, expresando de esta forma el mito de la diosa ligada a la «vinculación tradicional de la mujer con el mar como madre de todas las criaturas» (Jones, 2006: 144). La caracola marina, como todas las conchas, se relaciona con el arquetipo de luna-agua, gestación-fertilidad y con las aguas primordiales. De este modo, las representaciones femeninas de la fecundidad pueden presentarse como figuras de la profundidad acuática o telúrica como ocurre con la diosa Sarasvati, «diosa de las aguas madres, donadora de 
vida y de posteridad, portadora del alimento, de la leche, de la semilla y de la miel, asilo de toda prueba, inviolable refugio» (Durand, 1981: 190).

Eglé Rakauskaité nos presenta el arquetipo del descenso y el retorno al útero materno en su obra In Honey, una instalación de performance y video realizada en el Museo de Arte de Reikiavik en 1996. La artista se introduce en posición fetal en un recipiente lleno de miel como si fuera un útero, respirando a través de un tubo que simula un cordón umbilical. A. Jones nos describe esta obra: «Resplandeciente y amarillo como una yema de huevo, su cuerpo se mantenía conectado a un aparato para respirar que ponía de manifiesto su vinculación y su dependencia con el recipiente blanco en el que se encontraba, que acabó transformándose en un seno materno gigantesco del que dependía su vida» (2006: 189).

Para C. G. Jung, el huevo tendría que ver con la «cueva subterránea». Tanto en extremo oriente como en occidente el huevo filosófico de la alquimia se relacionaría con la intimidad del útero: «La alquimia es un regresus ad uterum. El orificio del huevo debe estar "herméticamente" cerrado: este último simboliza el huevo cósmico de la tradición universal» (Durand, 1981: 241). Esta imagen de seguridad es designada por G. Durand como símbolo de intimidad y descenso, ya sea en forma de acoplamiento ictiológico o de apelotonamiento materno, que exigirían «la excavación o la zambullida en el agua y la tierra hembra. La mujer —acuática o terrestre- nocturna, de adornos multicolores, rehabilita la carne y su cortejo de cabelleras, de velos y de espejos» (1981: 224).

Desde lo simbólico, artistas como Carolee Schneemann reformulan su sexualidad mediante su obra titulada Interior Scroll de 1975, donde el conducto vaginal de la artista se convierte en un espacio de iniciación donde se fusionan lo masculino y lo femenino. La vagina conducto del parto sería el primer laberinto que cruzamos al nacer y que Schneemann representa como una forma escultórica, recurriendo para ello a un ritual que se traduce en una performance que despierta fuerzas emocionales profundas no solo en ella, sino también en un público mayoritariamente femenino. Esta obra reivindicaría el poder de lo femenino en función de los sexos a través de la vagina a la que considera como un símbolo de transformación del cual se originaría el conocimiento sagrado, el éxtasis y el nacimiento:

Una cámara traslúcida de la que la serpiente es el modelo exterior: animada por su tránsito de lo visible a lo invisible, una espiral rodeada por la forma del deseo y los misterios generativos, atributos del poder sexual femenino y 
masculino. Este origen del «conocimiento interno» se simbolizaría como el indicador principal que une el espíritu y la carne en la veneración de la Diosa. (citado en Jones, 2006: 144).

En el Paleolítico superior existiría una gran influencia de la diosa femenina como se puede comprobar en las culturas agrarias de Mesopotamia que poseían una religión de carácter cósmico basada en una «renovación constante y periódica de la vida, cuyo objeto de culto era la Diosa Madre. La tierra se percibía como madre y todos -animales, plantas y hombres-eran sus hijos y estaban sujetos a sus leyes» (Dunn, 1990: 28). Esta influencia de la Diosa Madre estará muy presente en la obra de Louise Bourgeois como vemos en las Lairs (Guaridas) de 1964, esculturas que la artista concibe como lugares protectores donde refugiarse, parecidos a úteros que cuelgan del techo, realizados a base de yeso, látex, resinas y materiales blandos que nos recordarían «las profundidades de un nido o de una gruta [...] la cálida penumbra del útero materno. La casa, la caverna, el nido, el laberinto y el cuerpo se transforman así en avatares de un mismo espacio primigenio» (Mayayo, 2002: 26). Estas obras enlazarían con Solf Landscape (Paisajes blandos) de 1967 donde se produce una metamorfosis del cuerpo humano y la Madre Tierra. En palabras de la propia artista: «Me parece evidente que nuestro cuerpo es una figuración que aparece en la Madre Tierra» (citado en Mayayo, 2002: 27). Bourgeois enlazaría con esta herencia ancestral, como ella misma explica, ya que estas obras no solo serían antropomórficas, sino también «paisajes, en la medida en que cabría considerar nuestro cuerpo desde un punto de vista topográfico, con un territorio con montes y valles, cavernas y agujeros» (citado en Mayayo, 2002: 27). Para H. Biedermann, los órganos femeninos como la vagina y el útero estarían relacionados con las cavernas y las cuevas, ya que penetrar en estos recintos haría «referencia a la búsqueda de un sentido de la vida en las profundidades de los estratos inconscientes, heredados, del inconsciente materno...» (Biedermann, 1996: 144).

Kiki Smith también representará la maternidad y la fecundación mediante úteros de bronce, cordones umbilicales hechos de papel enrollado y partes anatómicas del cuerpo humano o sus secreciones como esperma de cristal, siendo expresiones «de la sensibilidad “femenina estereotípica”» (Heartney, 2008: 287). Sus esculturas presentan un cuerpo humano desnudo con las piernas chorreando leche materna, sangre y semen. J. Chevalier, y A. Gheerbrant señalan como habría una relación de la leche con el semen en el lenguaje tántrico, ya que «la leche es la boddhichitta (pensamiento y semen a la vez) elevándose 
hacía el centro umbilical, el manipürachacra» (Chevalier y Gheerbrant, 1990: 632), el semen sería «potencia de la vida» mientras que la leche se asociaría al fuego celeste o uránico, siendo símbolo de inmortalidad y «de alimento y fecundidad en los planos físicos» (Chevalier y Gheerbrant, 1990: 633). H. Biedermann afirma que, en la alquimia, la leche junto con la sangre serían «uno de los símbolos para los dos principios primarios, azufre y mercurio» (Biedermann, 1996: 261), como vemos en la obra de Stoltzius titulada Chymisches Lustgärtlein de 1624, donde se afirma que «de la blanca leche y la roja sangre se produce “mucho oro pesado”» (citado en Biedermann, 1996: 262), por lo que este autor concluye que la leche en este texto podría ser «un eufemismo alegórico por esperma, ya que según una antigua teoría de la procreación, el origen de la vida se producía por la unión del blanco esperma y la roja sangre de la menstruación» (Biedermann, 1996: 262). El arquetipo de la sangre será utilizado por Ana Mendieta para reforzar su condición de artista mujer en su action painting de 1974 titulada Body Tracks, donde se embadurna sus pechos y manos con sangre que impregna sobre la pared dejando su silueta. Según la observación de Mendieta sobre esta performance: «Creo que es algo mágico muy poderoso. No lo considero una fuerza negativa» (citado en Jones, 2006: 63).

Como hemos visto, la mujer desde un punto de vista místico se expresaría mediante ritos donde la esencia femenina se convertiría en «un fluido que une la brecha existente entre el plano de la realidad donde habita nuestro consciente cotidiano y ese otro dominio desconocido, difícil de explicar, que no obstante vive en todos nosotros» (Dunn, 1990: 193). De este modo, en el mundo de los mitos y las religiones habría paralelismos entre la simbología que presentan las distintas culturas y los procesos energéticos y psicológicos de la mujer, como ocurre con en el doble poder creativo y destructivo de la diosa Kali que lo aniquila todo, devolviendo al mundo «su forma natural para que los dioses puedan regresar, portando una visión indivisa de la vida» (Dunn, 1990: 89). La diosa Kali sería la representación de los opuestos, ya que personificaría la creación y la destrucción, apareciendo «como Madre Negra, a horcajadas sobre su consorte muerto, Shiva, comiéndole las entrañas mientras su yoni es devorado por el ligam de él» (Dunn, 1990: 89).

Esta mitología se traduciría en el ciclo menstrual femenino, donde habría una ambivalencia de creación a través de la destrucción, metáfora de los dos polos de la sexualidad femenina. Uno de ellos se alcanzaría cuando la mujer ovula «y se expresa en términos de receptividad y entrega» (Dunn, 1990: 36). En este periodo la mujer es más 
fértil y por lo tanto se puede producir con más facilidad la concepción: «El otro vértice de la sexualidad se manifiesta antes, durante y después del flujo menstrual, y es multiorgásmico y no fértil» (Dunn, 1990: 36). Según Dunn, en la mujer operarían mecanismos opuestos que se manifestarían en la diosa con sus múltiples facetas y en su estado de devenir constante, por eso la mujer sería «la perfecta mediadora para expresar las fuerzas que actúan en el consciente y en el inconsciente de la humanidad y de la existencia. Su familiaridad natural con su ser instintivo halla un medio de expresión a través del cuerpo en el parto, en la menstruación, en la sexualidad y en la maternidad» (193).

E. Pérez de Carrera señala como tendríamos que buscar la percepción de lo mistérico a través de la sublimación del sexo, el cual sería «un rito arquetípico en sus dos sentidos de memoria de futuro» (2004: 137), afirmando como el subconsciente colectivo tendría varios niveles, siendo uno de ellos el que relacionaría al ser humano con su consciencia superior, mediante un camino individual subjetivo y espiritual, poseyendo resortes energéticos que le harían «sentir, soñar y escuchar su futuro» (135). Para L. Irigaray, en la pareja humana, hombre y mujer, existiría una atracción que surgiría «del instinto y que deviene humanidad y divinidad» (2016: 29). Así, tendríamos el deseo de entrar en relación con el otro, pero no para «poseer o apropiarse del otro, lo cual equivale a una necesidad real o imaginaria de reducir al otro a mí mismo o mi propiedad», sino que hay que mantener y crear un espacio mediante «la atracción recíproca entre ambos, gracias al respeto de la trascendencia de cada uno por parte del otro» (Irigaray, 2016: 28).

\section{ANIMUS: EL PODER MASCULINO EN EL ARTE DE LO FEMENINO.}

Las mujeres consumiríamos imágenes de lo femenino y del animus en su aspecto femenino que habrían sido proyectadas por nuestra cultura a través de la psique masculina que crearía y procesaría este tipo de imágenes. El animus y el anima nos ayudarían a ver «cómo nuestras psiques luchan con los demonios internalizados de una cultura sexista» (Wehr, 2010: 79). Para Wehr es importante «que nos nutran y fortalezcan tanto las imágenes masculinas como las femeninas» (78). El concepto de animus se debe desontologizar para convertirlo como especifico de la cultura, ya que la psique y la cultura estarían relacionadas de forma dialéctica. Por lo tanto, el animus se convertiría en «un 
concepto útil si nos damos cuenta de que la psique internaliza imágenes además de proyectarlas» (Wehr, 2010: 79).

En las manifestaciones artísticas de las mujeres vemos como nuestra psique funcionaría como creadora y procesadora de imágenes, como señala J. Hillman, de manera que la mujer puede realizar su lado masculino a través del animus como logos, es decir, como capacidad para el pensamiento racional, para el poder, y la autoridad que serían los pasos que la escuela de C. G. Jung habría reconocido hasta el momento, aunque según esta autora las mujeres tendrían que encontrar «imágenes femeninas del pensamiento y la autoconfianza» para así dar «la espalda al rechazo y el temor que siente nuestra sociedad ante el poder, la autoridad y la racionalidad de las mujeres» (Hillman, 2010: 78).

C. G. Jung afirmaba como en las edades primitivas los conceptos instintivos se originaban en la mente del individuo, de forma que la mente consciente los integraba en un sistema psíquico coherente mediante símbolos, pudiendo comprobarse como las artistas actuales al igual que ellos serían capaces de canalizar a través de sus obras estas aportaciones que provienen del inconsciente y de los instintos donde aparecerían numerosas representaciones relacionadas con nuestra bisexualidad psíquica. Las artistas mujeres han tratado de fusionar en su obra el poder fecundador de la mujer manifestando al mismo tiempo su lado masculino, como vemos en la obra de Louise Bourgeois titulada Fragile Golden (Diosa frágil) de 1970, donde representa el arquetipo de la madre perteneciente a una serie de «mujeres fálicas» realizada entre 1969 y 1970, donde funde lo masculino y lo femenino en la imagen de la Diosa Madre: «De marcado acento surrealista, estas “mujeres fálicas” nos recuerdan el carácter bipolar que ha tenido siempre la maternidad en la imaginaria occidental (la Madre buena/la Madre mala; la Diosa nutricia/la diosa letal)». (Mayayo, 2002: 33).

Esta ambivalencia será frecuente desde el comienzo de su carrera artística como ocurre en su obra Femmes-maison de 1946-47, donde representa el cuerpo fusionado de una mujer y la arquitectura de una casa, donde se desarrolla el drama familiar de la artista y al mismo tiempo se convierte en el «escenario de los placeres de la maternidad [...] imagen de su identificación secular con un papel exclusivamente nutricio y reproductor» (Mayayo, 2002: 13-14). Femmes-maison inauguraría «un juego de oposiciones (entre lo inanimado y lo orgánico, lo rígido y lo maleable, lo frágil y lo sólido, lo geométrico y lo fluido), que será constante en años venideros en la obra de Bourgeois» (Mayayo, 2002: 
14). Estas fusiones vuelven a aparecer al final de su vida, en el año 2008, en su obra titulada The Maternal Man, un dibujo sobre papel que representa el perfil desnudo de una figura que esgrime un falo erecto, presentando al mismo tiempo un vientre abultado típico del embarazo en cuyo interior por transparencia se aprecia el hijo que está gestando. Esta simbología andrógina nos retrotraería a las imágenes primitivas como la de Laussel (Dordoña), donde se ha encontrado una figura doble incisa en la roca en la que se puede ver dos figuras contrapuestas encerradas en un contorno ovoide perteneciente al solutrense inferior. S. Giedion cree que en esta época ya existía este símbolo de fertilidad representado por un ser doble capaz de autorregeneración, que también interpreta como un ser andrógino por el curioso entrelazado de las dos figuras: «Sea cual sea la significación exacta de la figura doble de Laussel, todas las interpretaciones apuntan a un proceso de fertilidad. Es muy posible que este curioso objeto represente la manifestación más temprana de un símbolo andrógino» (Giedion, 1991: 287).

También Rebeca Horn en 1970 fusiona lo masculino y lo femenino en su pieza de performance titulada Unicorn, vistiéndose con un cuerno único blanco que sale de la parte superior de su cabeza, sujetado con correas que rodearían su cuerpo a la manera de Frida en su obra La columna rota de 1944. En esta performance, Rebeca Horn sintetizaría una etapa en la vía de la diferenciación que consistiría en el desarrollo psíquico o unidad asexual, que también tendría que ver con la sublimación sexual: «Este cuerno único se ha comparado a una verga frontal, a un falo psíquico» (Chevalier y Gheerbrant, 1999: 1037). El unicornio representaría un símbolo de la virginidad física y de la fecundación espiritual. Para los alquimistas sería una imagen del hermafrodita que transciende la unión de la doble sexualidad, mientras que en la edad media se convertiría «en símbolo de la encarnación del Verbo de Dios en el seno de la virgen María» (Chevalier y Gheerbrant, 1999: 1037).

Wehr nos sugiere que las mujeres no tenemos por qué rechazar las imágenes masculinas, sino que no debemos usar estas imágenes «como una forma fraudulenta de conseguir poder femenino y pensamiento legitimador femenino» (Wehr, 2010: 78), ya que si solo nos limitamos a reproducir una situación de poder que existe en la sociedad no lograríamos liberar en las mujeres su animus. Aunque este hecho no impide que las mujeres reconozcamos el sexismo y tratemos de extirparlo para que «la terapia sea liberadora» (Wehr, 2010: 78). C. Zweig cree como lo masculino padecería un desequilibrio por la pérdida de lo femenino en las mujeres, por lo que tendría que 
producirse una renovación, un esclarecimiento y un renacimiento: «A medida que el arquetipo de lo femenino consciente se despliega en la consciencia, su arquetipo aliado cambia también. Tampoco hemos conocido nunca lo masculino consciente. Hemos confundido el principio de poder patriarcal, que controla y altera la naturaleza a toda costa, con lo masculino» (2010: 257).

\section{EL CARÁCTER BISEXUAL DEL SER HUMANO COMO META UNIFICADORA}

La reunión de los contrarios sería un proceso definido por C. G. Jung como de individuación constituyendo la distinción entre el yo empírico y el del hombre universal, siendo este hecho de vital importancia, ya que tendría que ver con nuestra evolución. Este proceso de integración de los opuestos estaría dirigido no por el yo consciente, sino por las tendencias arquetípicas e instintivas de lo inconsciente, manifestándose como un movimiento espontáneo hacia la totalidad, integridad y diferenciación de las potencialidades innatas del individuo, es decir, como el proceso de la constitución y particularización de la esencia individual, de la conversión en el «sí-mismo» que sería un arquetipo que compensaría nuestro conflicto interior-exterior, siendo la meta de la vida: «Se alcanza la meta de la individuación con la sensación del sí-mismo como algo irracional, un ente indefinible al que yo se opone ni está sometido, sino del que depende y en torno al que gira en cierto modo como la Tierra alrededor del Sol». (Jung, 2019: 104105)

D. De Bus señala como el camino de individuación significaría que el ser humano se ponga al unísono con su verdadera naturaleza, de manera que cuando este proceso psicológico se pone en marcha la vida del individuo comenzaría a ser «regida por un centro de gravedad y una organización que incluye realidades transpersonales e inconscientes» (2010: 90). Las formas de regir nuestra vida personal a través de esta regencia del Yo irían cambiando a medida que continuamos el proceso de individuación. El Yo apoyaría «una unión de opuestos interiormente reconciliados», de manera que buscaríamos en el entorno nuestro opuesto interior que nos daría «sanación y conocimiento» (Bus, 2010: 91). Sin embargo, no solemos hacer este viraje hacia el interior: «Esta imágenes, cuando se proyectan sobre otra persona en una relación, aportan posibilidades instintivas, sexuales, eróticas, afiliativas y espirituales» (Bus, 2010: 91). El proceso de individuación significaría un sacrificio que propiciaría la ampliación de 
nuestra consciencia identificando este proceso con «una plenitud omniabarcante más que una perfección puntual» (Bus, 2010: 98-99).

La artista Katharina Steverding no rechazaría su lado masculino y trataría de comprender su lado opuesto. En 1973 realiza su obra Transformer, representando su rostro como una gran máscara donde imita al hombre y viceversa, mediante un montaje fotográfico con su compañero Klaus Mettis, cuyo peinado y maquillaje serían tan idénticos que no se distinguían el uno del otro. La artista confiesa que mediante este tipo de manifestaciones se pone «en el papel del hombre para comprender el punto de vista contrario», afirmando que «la conquista de otro género tiene lugar en uno mismo» ( en Jones, 2006: 141). Esta acción de Steverding tendría que ver con el término empleado por C. G. Jung llamado persona, que sería la imagen representativa del arquetipo de la adaptación a la realidad externa y a la colectividad, apareciendo «en los sueños bajo el aspecto de ropas, uniformes y máscaras» (Witmont, 2010: 39). Estas representaciones jugarían con la confusión de los sexos como explica E. Pérez de Carrera, que afirma como habría otro tipo de arquetipos conscientes indiciados por los intereses, que serían los modelos o estereotipos que apresarían al individuo entre dos mundos, a los que define como lo «colectivo aparencial» y la «imagen de espejo de un sueño» (Pérez de Carrera, 2004: 135), de forma que, en este estado de confusión, se estaría presentando el mito sexual como algo que estaría influyendo en toda nuestra vida, a lo que habría que añadir el fenómeno de los papeles cambiados o confusos:

En la sociedad humana se repite un fenómeno inverso a la mayoría de las especies animales: la hembra se viste de colores y el macho se uniforma de gris, y paralelamente, desde una estructura morfológica bípeda y erecta, la mujer es, dentro de los llamados mamíferos, la hembra que más esconde el sexo, y el varón, con respecto a los otros machos, quien lo exhibe de forma más evidente. (Pérez de Carrera, 2004: 135)

Gran parte de las divinidades de la luna y la vegetación tendrían una doble sexualidad como vemos en «Artemisa, Atis, Adonis, Dionisios, algunas divinidades indias lo mismo que otras australianas, escandinavas o chinas, tienen una sexualidad muy variable. De ahí esas curiosas diosas barbudas como Cibeles frigia, la Dido-Astarté cartaginesa, la Fortuna y la Venus barbata romana» (Durand, 1981: 277). C. G. Jung en su obra maestra Mysterium Coniunctionis afirma que los alquimistas concebían la Luna como «un reflejo de la feminidad inconsciente del hombre, pero también es el principio de la psique 
femenina» (Wehr, 2010: 67). Este arquetipo de lo femenino tendría su resonancia en ambos sexos «especialmente en su aspecto maternal y de diosa» (Wehr, 2010: 69). Este sentido simbólico es recogido por la artista Judy Chicago en su obra titulada The dinner Party de 1979, donde lleva a cabo su gran instalación feminista en forma de banquete triangular, invitando metafóricamente a mujeres de la civilización occidental y de su mitología, representadas por treinta y nueve platos de cerámica pintados a mano donde aparece la imagen de la vulva a la que considera el «núcleo central» femenino, con nombres como la Diosa Primordial, la Diosa Fértil, Ishtar, Kali, Sofía o la Diosa Serpiente entre otras, revindicando así la caída del matriarcado y la opresión patriarcal a través de estos mandalas, símbolos del «sí-mismo» que nos enfrentarían a un camino de cambio y reevaluación tan presente a lo largo de su trayectoria. En 1970 se cambiará de nombre para así poder ser reconocida como mujer artista, pasando a llamarse Chicago en vez de Gerowitz; la creadora posará vestida de boxeador con una sudadera con su nuevo nombre y en el mismo cuadrilátero donde entrenaba Mohamed Alí en su acción titulada Boxing Ring, donde parodia los anuncios y carteles sexistas de artistas masculinos presagiando como ella misma escribe en su biografía «el momento en que las mujeres de todo el país salieron a luchar para provocar de alguna forma un cambio en la profunda discriminación del mundo del arte» (citado en Jones, 2006: 137).

El arte de las mujeres nos redescubriría otra dimensión del ser humano mediante imágenes y representaciones arquetípicas capaces de desarrollar nuestra consciencia y captar aspectos ocultos de nuestro ser que nos lleven a otro modelo social donde la fuerza y el poder de lo femenino comiencen a cambiar nuestras vidas. L. Nochlin, en su ensayo de 1971 titulado ¿Por qué no ha habido grandes mujeres artistas?, llega a la conclusión de cómo sería nuestro modelo social e institucional el que a lo largo de nuestra historia no estaría valorando realmente a la mujer artista en toda su dimensión creativa, frente a sus contemporáneos masculinos, señalando como el arte ya no sería «una actividad autónoma y libre de un individuo superdotado “nfluido” por los artistas anteriores y, de forma más vaga y superficial, por las “fuerzas sociales”» (1971: 7).

Las mujeres artistas ya estarían demandando una concepción más femenina-maternal de nuestro mundo, buscando esta reconciliación de los contrarios, como afirmaba Louise Bourgeois acerca de su instalación titulada I Do, I Undo, I Redo de 1999-2000: «En las relaciones con los demás, ha habido una reparación y se ha alcanzado la reconciliación. 
Las cosas han regresado a la normalidad. Vuelve a haber esperanza y amor» (citado en Morris, 2004: 72).

\section{CONCLUSIONES}

El arquetipo de la madre tendría que ver con modelos universales de nuestra psique, teniendo su influencia en ambos sexos, especialmente en su aspecto de símbolo unitivo universal que se manifestaría en el arte como un ser bixesuado, capaz de aglutinar polaridades y de enfrentar al artista y al espectador con las profundidades de su pasado evolutivo, pero también con nuestro futuro. Esta identidad de los sexos se expresaría en el arte mediante arquetipos relacionados con el poder fecundador de lo femenino, que manifestaría al mismo tiempo nuestro poder masculino, a través de una obra profundamente ritualizada que las artistas mujeres utilizan como crítica social o como búsqueda personal como vemos en Louise Bourgeois, Carolee Schneemann, Rebeca Horn, Miriam Schapiro, Mary Beth Edelson, Kiki Smith, Ana Mendieta, Eglé Rakauskaité o Judy Chicago, entre otras.

\section{BIBLIOGRAFÍA}

Biedermann, Hans. Diccionario de símbolos. Barcelona: Paidós, 1996.

Bus, David de. El yo es una diana móvil: el arquetipo de la individuación. En: Downing, Christine (ed.). Espejos del yo, Imágenes arquetípicas que dan forma a nuestras vidas. Barcelona: Kairós, 2010, pp. 87-99.

Chevalier, Jean; GheERBRAnt, Alain. Diccionario de los símbolos. Barcelona: Herder, 1999.

Cirlot, Juan. Eduardo. Diccionario de símbolos. Barcelona: Labor, 1969.

DunN, Manuela. Diosas. La canción de Eva. Barcelona: Ediciones Robinbook, 1990.

DURAND, Gilbert. Las estructuras antropológicas de lo imaginario. Introducción a la arqueología general. Madrid: Taurus, 1981.

Franz, Marie-Louise von. Alquimia. Introducción al simbolismo. Barcelona: Océano, 1999.

GIEDION, Sigfried. El presente eterno: los comienzos del arte. Madrid: Alianza Editorial, 1991.

HeARTney, Eleanor. Arte hoy. Barcelona: Phaidon Press Limited, 2008.

IRIGARAY, Luce. En el principio ere ella. Un retorno al origen griego arcaico de nuestra cultura. Barcelona: La llave, 2016. 
Hillman James. Anima: Guía hacia el alma. En: Christine Downing (ed.). Espejos del yo, Imágenes arquetípicas que dan forma a nuestras vidas. Barcelona: Kairós, 2010, pp. 58-60.

JunG, Carl Gustav. Las relaciones entre el yo y el inconsciente. Barcelona: Paidós, 1993. Jung, Carl Gustav. AION. Contribución a los simbolismos del sí-mismo. Barcelona: Paidós, 1995.

JunG, Carl Gustav. Recuerdos, sueños, pensamientos. Barcelona: Seix Barral, 1996.

JunG, Carl Gustav, et al. El hombre y sus símbolos. Barcelona: Caralt, 1997.

JunG, Carl Gustav. El libro rojo. Buenos Aires: El hilo de Ariadna, 2019.

JONES, Amelia. El cuerpo del artista. London: Phaidon, 2006.

MAyAyo, Patricia. Louise Bourgeois. Hondarribia: Nerea, 2002.

MORRIS, Frances. Louise Bourgeois. Tejiendo el tiempo. Málaga: CAC Málaga, 2004.

Nochlin, Linda. ¿Por qué no ha habido grandes mujeres artistas? En: Cordero Reiman,

Karen; Sáenz, Inda. Crítica feminista en la teoría e historia del arte. México, DF:

Universidad Nacional Autónoma de México, 1971, pp. 17-41.

PÉREZ DE CARRERA, Eduardo. 49 respuestas a la aventura del pensamiento. Tomo I.

Madrid: Fundación Argos, 2004.

Reckitt Helena; Phelan, Peggy. Arte y feminismo. Barcelona: Phaidon Press Limited, 2005.

Sorrosal Zumeta, Nelida, Elogio a la maternidad. En: Medicina Naturista. 2019, vol. 13, núm. 2, pp. 33-39.

WALKER, Mitchell. El doble ayudante interior del mismo sexo. En: Downing, Christine (ed.). Espejos del yo, Imágenes arquetípicas que dan forma a nuestras vidas. Barcelona: Kairós, 2010, pp. 81-86.

WEHR, Demaris. Animus: el hombre interior. En: Downing, Christine (ed.). Espejos del yo, Imágenes arquetípicas que dan forma a nuestras vidas. Barcelona: Kairós, 2010, pp. 61-80.

WhitMont, Edward C. La persona: la máscara que usamos en el juego de vivir. En: Downing, Christine (ed.). Espejos del yo, Imágenes arquetípicas que dan forma a nuestras vidas. Barcelona: Kairós, 2010, pp. 39-44.

ZWEIG, Connie. Lo femenino consciente: nacimiento de un nuevo arquetipo. En: Downing, Christine (ed.). Espejos del yo, Imágenes arquetípicas que dan forma a nuestras vidas. Barcelona: Kairós, 2010, pp. 246-257. 